\title{
O estado quebequense diante dos desafios da diversidade etnocultural ${ }^{1}$
}

\section{The Québécois State and the Challenges of Ethnocultural Diversity}

\author{
Alain-G. Gagnon ${ }^{2}$ \\ François Boucher ${ }^{3}$
}

Recebido em 25 de março e aprovado em 12 de abril de 2017.

Resumo: O presente texto retraça, à luz do contexto internacional, a trajetória quebequense em matéria de integração e de gestão da diversidade. Destacando as diferentes tendências que marcaram a evolução das políticas e iniciativas do Estado do Quebec desde meados dos anos 1960, Alain-G. Gagnon e François Boucher se concentram em examinar os fundamentos de uma abordagem cujo enfoque principal é a participação de todos em uma sociedade francófona e plural. A implantação deste programa é situada, inicialmente, no contexto mais amplo da instauração de regimes pluralistas nas democracias liberais e, então, do refluxo que estas sociedades registraram contra o reconhecimento do pluralismo cultural e religioso na virada dos anos 2000. Os autores apresentam, em seguida, as grandes etapas do desenvolvimento do modelo quebequense de gestão da diversidade, desde a redefinição da maioria de origem canadense-francesa como pilar de uma sociedade francófona de acolhida, até a formulação progressiva de um âmbito decididamente cívico de coabitação. Evitando, até o presente momento, a armadilha do retorno ao assimilacionismo, como é o caso em várias sociedades europeias, este âmbito será tanto mais promissor quanto ele continuar a apostar na inclusão, na luta contra a discriminação e no intercâmbio sustentado entre cidadãos de diferentes origens. Assim, o desenvolvimento da abordagem quebequense em matéria de integração deve, hoje, passar pelo aprofundamento das práticas que favoreçam o diálogo entre os diferentes componentes da sociedade quebequense, a luta pela justiça social e a busca de uma maior igualdade cidadã.

Palavras chaves: Quebec. Diversidade Etnocultural. Laicidade. Interculturalismo. Imigração.

Abstract: The current text retraces, in the light of the international context, the
Quebecois path in terms of integration and management of diversity. Highlighting the
different tendencies that marked the evolution of the politics and initiatives of the State
of Quebec since the mid 1960s, Alain-G. Gagnon and François Boucher reconsider the
main foundations of an approach whose main focus is to ensure the participation of all in
a francophone and plural society. The implementation of this program is placed, initially,
in the larger context of the deployment of pluralist regimes in the liberal democracies
and, later, in the backlash against the recognition of the cultural and religious pluralism
recognized in those societies in the early 2000. Thus, the authors present the major phases
of the development of the Quebec model regarding the management of diversity, from the
redefinition of the majority sharing a French-Canadian heritage as a pillar of a francophone 
host society, up to the progressive formulation of a framework deliberately embracing cohabitation. Avoiding until now the pitfalls of a return to the policies of assimilation, as we can see in some European societies, this framework will be more promising if it invests in inclusion, in the fight against discrimination and in solid exchanges between citizens from different backgrounds. Thereby, the development of a Quebecois approach to integration must focus nowadays on enhancing the practices that favour dialogues between different components of Quebec society, the pursuit of social justice and the quest of a greater citizenship equality.

Keywords: Québec. Ethnocultural diversity. Secularism. Interculturalism. Immigration.

Os países da democracia liberal se caracterizam, de modo geral, pela sua propensão em acomodar a diversidade. A partir dos anos 1970, os Estados Ocidentais rejeitaram a exigência da assimilação a fim de permitir às minorias etnoculturais se autogovernarem ou participarem plenamente da vida coletiva sem que fosse preciso que eles abandonassem as práticas culturais ou religiosas que expressam a sua identidade distinta. Contudo, pode parecer, à primeira vista, que, há cerca de uma década, este movimento de abertura ao pluralismo cultural perdeu seu fôlego. Evoca-se, em diversos países, a "morte do multiculturalismo" e o refluxo contra o pluralismo. Neste texto, nós situamos os debates sobre a integração dos novos imigrantes no Quebec no interior deste contexto sociopolítico internacional. Nós lançamos um olhar histórico a fim de destacar a evolução da abordagem do Estado Quebequense em matéria de integração e inclusão da diversidade etnocultural. Desta maneira, nós demonstramos que, longe de exprimir uma rejeição ao pluralismo e da abertura à diversidade, esta evolução testemunha, na verdade, os esforços do Quebec para instaurar sua própria política de gestão da diversidade. Após apresentarmos as grandes linhas dos debates sobre a diversidade no plano internacional, acordando uma atenção especial ao contexto europeu, nós destacamos os desafios contemporâneos da diversidade no Quebec e retraçamos a evolução dos esforços do Estado Quebequense em matéria de inclusão e integração dos novos imigrantes. Nós concluímos que, ao longo dos últimos quarenta anos, o Quebec gradualmente se distanciou da assimilação e tendeu à desenvolver uma política focada na promoção do francês e na plena participação e inclusão de todos ${ }^{4}$. 


\section{O contexto internacional}

A abertura dos Estados Ocidentais à diversidade se traduz de diversas maneiras, seja pelas políticas de contratação sensíveis à presença de coletividades diferenciadas no território, pela adoção de políticas de ensino nas línguas originárias, pela valorização dos aportes históricos dos grupos à edificação da sociedade de acolhida, pelo apoio financeiro aos grupos etnoculturais quando da implantação de instituições específicas (por exemplo, no momento da adoção da política canadense de multiculturalismo) seja pela vontade de fazer convergir os aportes dos grupos à consolidação de uma cultura compartilhada proposta ao conjunto dos cidadãos. É possível enumerar outros importantes exemplos de políticas sensíveis à diversidade e à inclusão: pensemos nos esforços para aumentar a visibilidade de grupos etnoculturais nas instituições públicas e na esfera midiática, na implantação de currículos escolares voltados à tolerância e à diversidade cultural, na instauração de práticas de acomodações permitindo aos membros de grupos etnoculturais exibirem sua identidade ou praticarem sua religião ao mesmo tempo em que participam ativamente da vida pública e econômica (acomodações razoáveis nas instituições públicas e nos locais de trabalho).

A partir do início dos anos 1970, os Estados Ocidentais buscaram responder aos desafios postos pela diversidade etnocultural, adotando políticas que visavam a proteger os direitos das coletividades minoritárias e a reconhecer a legitimidade das expressões das identidades de naturezas cultural, étnica, nacional, racial e religiosa. Esta virada multiculturalista não passou despercebida nos meios acadêmicos, de tal maneira que ao longo dos anos 1990, o multiculturalismo e a questão do pluralismo identitário ocuparam um papel preponderante na literatura científica. Alguns pesquisadores até mesmo expressaram a ideia segundo a qual assistíamos à emergência de um consenso acerca da legitimidade das políticas do multiculturalismo (KYMLICKA; NORMAN, 2000, p. 4; KYMLICKA, 2001, p. 39-42). Neste contexto, os governos se sentiam apoiados no momento de adotar políticas públicas tendo em vista o reconhecimento da legitimidade das identidades etnoculturais na esfera pública e, particularmente, aquelas das coletividades minoritárias ${ }^{5}$. 
Este consenso, contudo, foi abalado ao longo dos anos 2000. Na esteira do refluxo contra o islã registrado na sequência dos acontecimentos de 11 de setembro de 2001, pudemos detectar três fenômenos distintos: 1) uma acentuação da inquietação das populações estabelecidas a respeito das pessoas que (aparentemente) gostariam de se beneficiar dos sistemas de seguridade social, que as populações já instaladas teriam se dotado ao longo dos anos e que corriam o risco de se desintegrarem devido às conjunturas econômica e política instáveis; 2) a persistência da insegurança econômica e o alargamento das zonas de conflito de grande escala; 3) a vontade dos novos cidadãos de recorrem, ao mesmo título que as comunidades já estabelecidas desde muito tempo, aos instrumentos políticos e jurídicos e às instituições para tornar conhecidas e valorizar as suas diferenças e preferências.

A legitimidade e a vontade de acomodar as identidades etnoculturais passaram a ser questionadas, em especial nos países da Europa Ocidental, os quais, no entanto, se encontravam a par das questões de diversidade. Nós testemunhamos, assim, a expressão de ansiedades culturais e identitárias quanto ao potencial destas sociedades, reconhecidas por suas capacidades de acolhimento, assegurarem um vivre-ensemble harmonioso e pacífico e manterem, ao mesmo tempo, certo controle sobre os marcadores definindo as identidades coletiva e nacional em relação à língua, ao aprendizado da história e à aquisição das normas culturais e sociais (PAPADEMETRIOU, 2012, p. 2-3). Estas ansiedades culturais também foram observadas em grande escala em vários Estados marcados, em diferentes níveis, pela imigração e pela diversidade, como a Austrália (ANG ET AL, 2006) e os Estados Unidos (HUNTINGTON, 2005; GLAZER, 1998). Em alguns Estados, os legisladores acreditaram ser essencial realizar assembleias públicas para tratar da amplitude das buscas identitárias. É neste contexto que a França conferiu, a partir de 2003, um mandato para a Comissão Stasi aprofundar as questões relativas à aplicação da laicidade na República Francesa, que o Quebec instaurou a Comissão Bouchard-Taylor, em 2007, para refletir sobre as práticas de acomodações ligadas às diferentes culturas e que, a partir de 2010, a Bélgica lançou suas próprias Assembleias da Interculturalidade, sob a direção de Marie-Claire Foblets e de Christine Kulakoswki. Estas consultas foram precedidas pela Comissão sobre o Futuro de uma Inglaterra Pluriétnica, de 1997, dirigida 
por Bhikhu Parekh. Nós devemos a essas comissões um importante trabalho de exploração das questões relativas ao vivre-ensemble. Em cada um destes casos, notamos uma abertura à diversidade religiosa ao mesmo tempo em que são sugeridos limites quanto ao porte de símbolos religiosos ostensivos e balizas compreendendo as celebrações religiosas e os feriados que as acompanham.

Ao longo dos trabalhos destas comissões, vários intervenientes descreveram as minorias etnoculturais oriundas da imigração como portadoras de valores incompatíveis com os princípios fundamentais da democracia liberal, como a igualdade entre os sexos e a tolerância às religiões e às práticas sexuais diferentes. Outros intervenientes perceberam as políticas do multiculturalismo como sendo passivas demais e encorajadoras da criação de enclaves etnoculturais, vivendo isolados dos demais membros da sociedade de acolhida.

Finalmente, alguns temeram que a manutenção de políticas do multiculturalismo pudesse acarretar na erosão do Estado providência e limitar a redistribuição de riquezas, o que acabaria por minar as bases da solidariedade (ENTZINGER, 2006, p. 177-201). Em todos estes exemplos, quer toleremos ou não os valores aparentemente diferentes e incompatíveis dos imigrantes, várias políticas concordavam que o efeito da fragmentação social ou ainda a erosão do Estado Providência iriam prejudicar a coesão social.

Estas críticas às políticas favoráveis ao respeito e ao reconhecimento da diversidade desembocaram em uma percepção amplamente difundida segundo a qual o multiculturalismo promovido nos anos 1990 teria resultado em um fracasso. Recordemos, por exemplo, que a chanceler Angela Merkel declarou que o multiculturalismo alemão estava "morto", uma ideia igualmente defendida por Nicolas Sarkozy e David Cameron. ${ }^{6}$ Estas tomadas de posição pública buscavam fazer produzir uma Europa que seria, a partir de então, fundamentada em políticas ditas de "integração cívica". Nos círculos acadêmicos, falou-se também em "recuo do multiculturalismo", de "um refluxo a respeito do multiculturalismo" ou de um "retorno da assimilação" (BRUBAKER, 2011; JOPPKE, 2004; VERTOVEC, WESSENDORF, 2010; SCHEFFER, 2011).

Para responder de maneira eficaz aos desafios mais recentes, os governos afirmaram querer tomar uma virada integracionista. O Primeiro Ministro britânico David Cameron propôs, então, substituir o multiculturalismo de Estado por um "liberalismo 
musculoso" mais intransigente com relação às expressões da diversidade e que fizesse, ao mesmo tempo, a promoção ativa de uma identidade nacional forte, no objetivo de se opor, conforme ele declarou, ao avanço dos extremismos, em especial, aqueles do movimento islâmico ${ }^{7}$. A Alemanha de Angela Merkel, a França de Nicolas Sarkozy e a Inglaterra de David Cameron admitiram publicamente tomar esta via para avaliar o que eles denunciaram como sendo o comunitarismo. Esta virada consiste em exigir dos novos cidadãos que eles adotem as tradições e os costumes da sociedade de acolhida, o que ajudaria a reduzir a distância entre as diversas práticas cidadãs.

A instauração das mudanças políticas propostas visava a dar uma resposta firme às ansiedades identitárias a respeito da imigração e da diversidade, destacando as obrigações e os deveres dos novos imigrantes. Isto se traduziria por meio da introdução de novas exigências, como "testes de cidadania" e entrevistas, bem como de cursos permitindo obter um conhecimento adequado da língua, da história e das normas culturais próprias à sociedade de acolhida. A aprovação nestes testes se tornou, algumas vezes, até mesmo uma condição sine qua non da obtenção da cidadania ou do visto de residência (GOODMAN, 2012; JOPPKE, 2012). Os resultados foram decepcionantes, pois a reação foi geralmente forte, provocando consideráveis tensões sociais. Esta virada integracionista foi acompanhada por um apoio oficial mais tímido às políticas do multiculturalismo em vários Estados, ainda que, na prática, as políticas públicas tenham sido mantidas e, até mesmo, seus orçamentos tenham sido aumentados pelos legisladores (KYMLICKA, 2012). O que nós observamos não é tanto a retirada do multiculturalismo, mas a adição, em paralelo, de políticas assimilacionistas.

No plano empírico, não foi demonstrado que as políticas do multiculturalismo poderiam levar à erosão da coesão social. Em verdade, nos parece que os países que adotaram políticas de diversidade favoráveis a uma cidadania universal não diferenciada reavivaram importantes tensões. Pensemos nas políticas francesas adotadas na esteira da Comissão Stasi, que levaram à interdição do uso do hijab nas escolas públicas e, posteriormente, às diversas propostas de interdição da burqa na Bélgica, na França e no Quebec. As discussões em torno destas propostas fizeram trazer de volta à superfície significativos temores no seio das principais comunidades de acolhida, que precisamos tomar em consideração. 
Segundo alguns estudos, haveria poucas diferenças mensuráveis entre os valores dos novos imigrantes e aqueles dos grupos majoritários já estabelecidos há muito tempo. Os novos imigrantes adeririam, ao menos no Canadá (SOROKA, JOHNSTON, BANTING, 2007), aos valores liberais e democráticos tanto quanto os membros da maioria etnocultural e o sentimento de pertença ao país das minorias imigrantes no país se compararia favoravelmente àquele dos membros da maioria (KYMLICKA, 2010). Da mesma forma, não haveria correlação entre a adoção de políticas de multiculturalismo e a erosão do Estado Providência (BANTING, KYMLICKA, 2005). O avanço das políticas de integração cívica, na Europa, não é acompanhado de um abandono das medidas visando a proteger os direitos das minorias. Parece-nos, ao contrário, que as políticas de integração cívica se justapõem às práticas existentes de reconhecimento e de acomodação da diversidade, sem, portanto, serem acompanhadas por um recuo das políticas de multiculturalismo já adotadas (BANTING, KYMLICKA, 2013). Os dados obtidos confirmam que as práticas de integração cívica "musculosas" raramente são adotadas pelos Estados, pois elas, geralmente, entram em conflito com o respeito dos direitos das minorias (JOPPKE, 2012). Além disso, enquanto certo endurecimento se instalou no seio dos países europeus ao longo dos anos 2000, uma concepção mais inclusiva da integração emergiu nas instituições europeias (JOPPKE, SEIDLE, 2012). Assim, uma concepção respeitosa da diversidade, proposta pelo Conselho da Europa, que considera a integração como um processo de adaptação mútua, foi adotada desde 2004. O Conselho aproveitou o momento para identificar "Princípios Fundamentais Comuns", que definem não apenas as obrigações dos imigrantes, mas também seus direitos e as responsabilidades da sociedade de acolhida (CONSEIL DE L'EUROPE, 2004).

É importante relembrar que grande parte das controvérsias suscitadas pela gestão da diversidade, em particular da diversidade oriunda da imigração, gira em torno da dimensão religiosa das identidades e das práticas próprias às minorias etnoculturais. Se a diversidade produz ansiedades identitárias, estas estão ligadas, sobretudo, às minorias religiosas, particularmente, associadas ao islã ${ }^{8}$ Assim, é em nome de uma visão bastante reduzida da laicidade e da separação entre as instituições políticas e o universo religioso (e dos objetivos que identificamos com a laicidade, por exemplo, a promoção da igualdade, 
da liberdade individual e da coesão social), que um grande número de medidas limitando a liberdade de exibir sua pertença religiosa foi adotado pelos legisladores. Pensemos notadamente na lei francesa de 2004 que proíbe o uso de símbolos religiosos ostensivos nas escolas públicas, ou ainda, nas leis francesa e belga, de 2010 e 2011, interditando o uso em todos os "locais públicos" (definidos da maneira mais ampla possível) elementos cobrindo o rosto ou ainda no referendo suíço de 2009 sobre a interdição da construção de minaretes. A laicidade se encontra, portanto, entrelaçada à questão da integração dos novos imigrantes, ainda que ela seja um dispositivo institucional inicialmente concebido para assegurar a coexistência entre os membros já estabelecidos em uma sociedade, que adotam crenças religiosas diferentes (BOUCHER, MACLURE, 2015).

Finalmente, um aspecto pouco estudado nestes últimos anos diz respeito à questão das políticas linguísticas nos Estados complexos (GAGNON, KEATING, 2012; CARDINAL, SONNTAG, 2014). Devemos reconhecer que os Estados bilíngues e multilíngues como a Bélgica, o Canadá e a Suíça geralmente devem superar desafios maiores que os Estados unilíngues, como a Austrália e a França. Assim, no caso do Quebec, como nós veremos, a perenidade do francês se manteve como uma preocupação constante para cada um dos partidos que se revezaram no poder desde o início dos anos 1970.

\section{$O$ contexto quebequense}

A sociedade quebequense se transformou desde o início dos anos 1960 e ela teve que demonstrar a sua capacidade de abertura para acolher novos migrantes em busca de um melhor futuro, que se juntavam à uma comunidade política em plena mutação. O Quebec também buscou instaurar e aplicar sua própria política de diversidade etnocultural desde o início dos anos 1980. Este período favorável à expressão da diversidade etnocultural conheceu auge ao longo dos anos 1990, através, entre outros, da adoção do enunciado No Quebec, para construirmos juntos 9 .

Ainda que no âmbito do país, o Quebec tenha sido o primeiro a se dotar de uma Carta dos Direitos e Liberdades da Pessoa (1975), ele foi o mais lento a se interessar pela questão da diversidade etnocultural, sendo mais levado a discutir, sobretudo, o papel da província em um Canadá binacional. Além disso, o Quebec não foi poupado das 
ansiedades identitárias relativas à integração, que caracterizaram várias outras sociedades de imigração, notadamente aquelas da Europa Ocidental. O Quebec e o Canadá não estiveram completamente abrigados de algumas atitudes censuráveis. Pensemos no recente avanço da islamofobia na mídia, na instrumentalização de temores relacionados ao uso do niqab para fins eleitorais, assim como nos casos de agressão ou de assédio de mulheres usando véus em espaços públicos. A vontade de modificar a Carta Quebequense dos Direitos e Liberdades da Pessoa para interditar o uso de símbolos religiosos ostensivos pelos funcionários públicos quando do debate sobre a Carta dos Valores ${ }^{10}$ constitui um afastamento em relação aos compromissos assumidos pelo Quebec em matéria de proteção dos direitos das minorias. Esta desvalorização do direito, visto como um entrave por alguns atores, teve como consequência abalar a relação de confiança no plano das trocas intercomunitárias.

A situação do Quebec é bastante diferente daquela dos países europeus. O refluxo contra o pluralismo parece ter sido mais fraco aqui que em outros contextos. Por exemplo, a província não tem nenhum partido xenófobo propondo um programa explicitamente anti-imigração, a exemplo do British National Party, do Front national, ou ainda, do Partij voor de Vrijheid. Isto se explica em parte pelas condições favoráveis à aceitação da diversidade que encontramos na província. Diferentemente da Europa, os países de origem dos imigrantes no Quebec são bastante diversificados, de maneira que a imigração não deu lugar à criação de uma grande comunidade originária de uma única e mesma fonte (como os argelinos na França e os turcos na Alemanha). Além disso, o Quebec não mantém relações pós-coloniais com as coletividades oriundas da imigração ${ }^{11}$. Finalmente, ele não compartilha fronteiras com nenhum país de origem de uma coletividade de migrantes e não enfrenta o problema de imigração ilegal e de sans-papiers, como nos Estados Unidos, na Espanha e na Itália.

Nas próximas seções, nós mostraremos que a trajetória histórica seguida pelo Quebec não vai em direção à rejeição do pluralismo. Esta trajetória se afastou gradualmente da exigência de assimilação e, ao longo dos últimos anos, apesar dos episódios da Carta dos Valores e da Crise das Acomodações Razoáveis ${ }^{12}$, o Estado quebequense reafirmou 
a sua vontade de assegurar a inclusão de todos, no respeito de suas diferenças. Nós distinguimos quatro fases neste percurso histórico:

1) A transição do Canadá Francês como referência comunitária primária ao Quebec enquanto sociedade de acolhida

Os anos 1960 constituem um momento chave na evolução do Canadá Francês e da emergência da sociedade quebequense. Por um lado, nós vemos o Canadá Francês se beneficiar da instauração da Comissão Laurendeau-Dunton (1963-1969), que contribui para sensibilizar os canadenses acerca do fato que os francófonos eram desfavorecidos no mercado de trabalho, tanto no setor privado quanto na função pública. Ao longo destes mesmos anos, o governo do Quebec lança inúmeras iniciativas nos campos da educação, da saúde e de infraestruturas a fim de dotar a província das melhores estruturas possíveis para a atração de empresas, ao mesmo tempo em que ele dá aos trabalhadores condições de emprego mais interessantes.

É também nesta época que a Comissão Parent (1963-1964), instaurada para investigar a situação da educação no Quebec, constata que o fenômeno de anglicização dos neo-quebequenses se intensificava e que isto poderia ameaçar, a longo prazo, o futuro dos francófonos. A questão era a de saber como favorecer a integração destes novos imigrantes em uma sociedade de acolhida preocupada com a preservação e a promoção do caráter francês do Canadá, mantendo, ao mesmo tempo, a paz social. Para enfrentar este grande desafio, as formações políticas concordaram em desenvolver gradualmente um conjunto de medidas que contribuíssem à redefinição da sociedade quebequense francófona como uma comunidade de acolhida. Neste contexto (e respondendo à Comissão Laurendeau-Dunton), a Comissão Gendron (1968-1973) recebeu da Assembleia Nacional do Quebec o mandato de estudar a situação da língua francesa e dos direitos linguísticos dos francófonos no Quebec. A Comissão Gendron recomendou "fazer do francês a língua comum dos quebequenses, ou seja, uma língua que, sendo conhecida por todos, possa servir de instrumento de comunicação nas situações de contato entre quebequenses francófonos e não-francófonos" (COMMISSION D’ENQUÊTE SUR LA SITUATION DE LA LANGUE FRANÇAISE ET SUR LES DROITS LINGUISTIQUES AU QUÉBEC, 1972, p. 154), como a sua recomendação inicial. 
É neste espírito que a ideia de definir a sociedade quebequense francófona enquanto comunidade de acolhida se impôs e abriu as portas à adoção da Carta da Língua Francesa, em 1977. A ideia central que se buscava à época era a de reconhecer à todos os quebequenses "o direito ao francês nos domínios da vida quebequense [e de fazer] desta língua um bem comum nacional, o bem comum de todos os quebequenses, o meio por excelência de coesão e de diálogo entre quebequenses de diversas origens e, ao mesmo tempo, o meio de expressão da identidade quebequense face ao mundo" (LAURIN, 1978, p. 145) ${ }^{13}$.

Em resumo, este é um período de transição durante o qual o grupo de referência, definido em termos étnicos e bastante homogêneos, opera uma passagem gradual de uma identidade ocasionalmente retraída e apreensiva à uma identidade afirmada em relação às outras culturas e consciente de seu aporte ao avanço dos direitos do indivíduo e das coletividades aqui e no plano internacional. Uma vez a identidade quebequense aliviada de uma parcela de suas características homogêneas, ela se tornou mais acessível aos neoquebequenses. Portadores de uma identidade diferenciada nos planos cultural, étnico e religioso, os novos quebequenses aderiram, gradualmente, a uma sociedade quebequense tornada pluralista no plano das ideias e das tradições, adotando, gradualmente, a língua francesa ao mesmo tempo como bem cultural e bem econômico.

2) De sociedade de acolhida à comunidade de pertença: elaboração de uma política de integração e de gestão da diversidade cultural de grande envergadura

Ao longo dos anos 1980, os governos se destacaram daquelas das décadas anteriores ao se revelaram cada vez mais sensíveis às expectativas dos imigrantes. É aliás neste âmbito que devemos situar a primeira grande política em matéria de gestão da diversidade no Quebec, que assume o provocador título de Tantas maneiras de ser quebequense $^{14}$ (1981). Desde então, o governo do Quebec se esforçou para elaborar uma política de integração e de gestão da diversidade etnocultural que fizesse do Quebec fosse ao mesmo tempo uma sociedade de acolhida e uma comunidade de pertença. Esta era foi aquela da convergência cultural e dos primeiros planos de ação governamentais focados em políticas de integração e de trocas intercomunitárias.

A partir deste momento, a ideia de convergência foi proposta como uma via substituta ao "mosaico canadense", associado ao multiculturalismo canadense 
(MINISTÈRE DES COMMUNAUTÉS CULTURELLES ET DE L'IMMIGRATION, 1981, p. 12). Diferentemente, por um lado, do "caldeirão" americano, que se fundamenta na assimilação e na primazia da cultura americana homogênea, e, por outro lado, do "mosaico canadense", o qual muitos suspeitam que faça a promoção da variedade etnocultural, deixando se constituir inúmeros focos de cultura e comunidades justapostas, o governo do Quebec buscou encontrar uma via adjacente, que permitisse conciliar a continuidade identitária - através da apropriação de uma língua comum e de valores compartilhados - e o respeito da diversidade enquanto princípio estruturante. No modelo da convergência cultural, a cultura quebequense francófona se apresenta como um foco de convergência cultural em torno do qual afluem os aportes dos grupos etnoculturais oriundos da imigração. Igualmente, todas as comunidades são chamadas para contribuir ao avanço de um "projeto cultural coletivo", aquele do desenvolvimento da cultura quebequense francófona. Da mesma forma, todas as comunidades culturais são convidadas a se juntar ao projeto cultural agregador portado, em primeiro lugar, pelos quebequenses francófonos. É nesta etapa na qual nasce a ideia de que o sucesso da integração dos imigrantes passa pela promoção das trocas e das interações entre as diferentes coletividades que formam a sociedade quebequense.

3) Enunciado de 1990: No Quebec, para construirmos juntos - auge da política de acolhida

O enunciado de política, No Quebec, para construirmos juntos, de 1990, inova, de modo singular, ao propor a noção de contrato moral como âmbito de condução por excelência das políticas de integração dos imigrantes no Quebec. Este enunciado se fundamenta em três princípios que confirmam a emergência de um Quebec plenamente moderno:

1.Uma sociedade na qual o francês é a língua comum da vida pública;

2.Uma sociedade democrática na qual a participação e a contribuição de todos são esperadas e favorecidas;

3.Uma sociedade pluralista aberta aos múltiplos aportes, nos limites impostos pelo respeito aos valores democráticos fundamentais e pela necessidade do intercâmbio intercomunitário. 
Neste modelo, a integração bem sucedida dos grupos etnoculturais oriundos da imigração passa pela promoção do francês, pela plena participação na sociedade e no mercado de trabalho e pelas trocas intercomunitárias. O desejo reafirmado de fazer do caráter francês um polo de integração para todos os imigrantes. Ele dá aval à proposta segundo a qual "a afirmação sem ambiguidade da coletividade francófona e de suas instituições como polo de integração dos novos imigrantes representa uma necessidade incontornável para assegurar a perenidade do caráter francês no Quebec e uma das balizas no interior da qual deve se inscrever o reconhecimento do pluralismo de nossa sociedade" (MINISTÈRE DES COMMUNAUTÉS CULTURELLES ET DE L'IMMIGRATION, 1990, p. 17).

É este o contexto no qual nasce e se impõe a noção de cultura pública comum, a qual vai adquirir sua notoriedade e visará a mobilizar todos os quebequenses em torno do francês enquanto língua comum, da laicidade, da igualdade entre homens e mulheres, do respeito aos valores democráticos, de um patrimônio comum e do reconhecimento dos direitos históricos da comunidade anglófona.

Uma das ideias mestras do enunciado de política era a de ultrapassar a dicotomia entre quebequenses e membros das comunidades culturais. É neste espírito que a proposta de um contrato moral explicitando os direitos e as responsabilidades permitiria a todos se dotar de uma sociedade compartilhada e de lançar uma reflexão sobre o vivre-ensemble, que valorizasse ideais mais universais de igualdade, de justiça, de dignidade e de solidariedade.

\section{4) Da virada cívica ao desenvolvimento da noção de interculturalismo}

Notemos, antes de tudo, que o enunciado de política No Quebec, para construirmos juntos continuou a inspirar todos os partidos políticos ao longo das duas últimas décadas. Contudo, sublinhemos também que, a partir da metade dos anos 1990, foi realizada uma transição em direção à instauração de um âmbito cívico assegurando a igualdade de todos os cidadãos. Este movimento se encarnou, inicialmente, em 1994, na criação do Ministério de Relações com os Cidadãos e teve tendência a tornar menos presente a noção de comunidades culturais, ainda que o programa de acesso à igualdade no emprego tenha sido mantido com o objetivo de, justamente, atenuar a sub-representação de membros de comunidades culturais na função pública quebequense. 
A instauração de um âmbito cívico assegurando a igualdade de todos os cidadãos esteve no centro da estratégia que levou à realização do Fórum Nacional sobre a Cidadania e a Integração, em 2000. A vontade exprimida por certos atores de fazer corresponder as noções de cidadania e de nacionalidade contribuiu para invalidar o conceito de cidadania, sobretudo junto aos quebequenses das comunidades culturais, e provocou um importante refluxo tornando difícil a sua reabilitação no curto prazo. Os trabalhos relacionados à realização dos Estados Gerais sobre a situação e o futuro da língua francesa, de 20002001, não conseguiram dar ao conceito de cidadania seu sentido pleno nem fazer a população quebequense adotá-lo.

Tendo sido, em certa medida, desacreditado junto dos membros das comunidades culturais, o conceito, no entanto promissor, de cidadania cedeu seu lugar à noção de interculturalismo, que saltou ao primeiro plano dos debates, sobretudo, a partir da Comissão Bouchard-Taylor sobre as práticas de acomodações decorrentes das diferentes culturas (2007-2008). A intenção que parece querer se impor, atualmente, é a de definir uma política de integração e de gestão da diversidade etnocultural própria ao Quebec, convidando todos os quebequenses à sua implementação. Dentre os elementos que parecem receber o maior número de apoios, destaquemos a igualdade entre os homens e as mulheres, a afirmação do francês como língua pública comum, a valorização do capital cultural e social das coletividades etnoculturais, as atividades de aproximação intercomunitária, o alargamento e o aprofundamento dos valores democráticos, a consolidação da laicidade, o respeito da Carta Quebequense dos Direitos e Liberdades do Indivíduo e a sua valorização.

A Comissão Bouchard-Taylor fez muito para sensibilizar o conjunto dos quebequenses sobre os valores que eles compartilham, ao lhes dar a palavra em diferentes ocasiões. Esta consulta pública, ainda que algumas vezes dolorosa, foi essencial pra a tomada em consideração de certos desconfortos e, sobretudo, da importância de se construir novas vias de colaboração em escala intercomunitária.

O governo do Quebec nunca se dotou de uma verdadeira política institucional que reivindicasse explicitamente a apelação "interculturalismo", apesar de muitos documentos se referirem às noções de "diálogo intercultural", de "aproximação intercultural", bem 
como de promoção de relações intercomunitárias harmoniosas (MINISTÈRE DES COMMUNAUTÉS CULTURELLES ET DE L'IMMIGRATION, 1990; MINISTÈRE DE L'IMMIGRATION ET DES COMMUNAUTÉS CULTURELLES, 2008). O relatório Bouchard-Taylor recomendou, notadamente, que "[p]ara melhor estabelecer o interculturalismo como modelo devendo presidir as relações interculturais no Quebec, que o Estado faça uma lei, um enunciado de princípio ou uma declaração, fazendo com que este exercício comporte consultas públicas e uma votação da Assembleia Nacional" (COMMISSION DE CONSULTATION SUR LES PRATIQUES D'ACCOMODEMENT RELIÉES AUX DIFFÉRENCES CULTURELLES, 2008, p. 269). A respeito deste ponto, o relatório constitui uma referência importante e comporta cinco elementos chaves definindo o interculturalismo quebequense: 1) o francês como língua comum das relações interculturais; 2) uma orientação pluralista, preocupada com a proteção dos direitos; 3) a preservação da necessária tensão criadora entre, por um lado, a diversidade e, por outro lado, a continuidade do núcleo francófono e o vínculo social; 4) o foco particular na integração e na participação; 5) a promoção da prática de interações (IBID., p. 121).

A ideia segundo a qual o interculturalismo constitui um modelo de gestão da diversidade etnocultural promissor e próprio ao Quebec é frequentemente debatida. Este termo nunca foi oficialmente definido pelo governo do Quebec. Além disso, ele é profundamente polissêmico. Alguns defendem que a especificidade do interculturalismo é dar uma prioridade à cultura da maioria (BOUCHARD, 2012). Contudo, o conceito de interculturalismo, tal como proposto na Europa, foca mais no diálogo intercultural que na importância de aderir à cultura do grupo majoritário da sociedade de acolhida ${ }^{15}$. Ainda, é difícil afirmar que exista um consenso sobre o significado a ser dado à noção de interculturalismo. Muitas noções de interculturalismo coexistem ${ }^{16}$. A isto, é preciso adicionar que, ainda que os principais defensores do interculturalismo estejam convencidos de que o interculturalismo seja uma solução diferente ao multiculturalismo (CONSEIL DE L'EUROPE, 2008; CANTLE, 2011; BOUCHARD, 2012; GAGNON, IACOVINO, 2016), um grande número de teóricos do multiculturalismo e do pluralismo tem dificuldades em identificar as diferenças substanciais entre multiculturalismo e interculturalismo (MEER, MODOOD, 2012; WEINSTOCK, 2013; KYMLICKA, 2016), 
as temáticas das trocas interculturais e do diálogo intercultural já figurando, desde muito tempo, nas políticas oficiais do multiculturalismo (ver, por exemplo, a lei canadense sobre o multiculturalismo, de 1988) e nas teorias do multiculturalismo ${ }^{17}$.

Ainda que ele não tenha definido o interculturalismo como um modelo de gestão da diversidade, o Estado quebequense continuou a reafirmar, nos últimos anos, a importância de promover as trocas interculturais a fim de lutar contra o isolamento das comunidades (MINISTÈRE DE L'IMMIGRATION ET DES COMMUNAUTÉS CULTURELLES, 2008; 2014). Os recentes trabalhos do Ministério da Imigração, da Diversidade e da Inclusão (que substituiu o Ministério da Imigração e das Comunidades Culturais) situam esta vontade no âmbito das escolhas estratégicas visando a lutar contra a discriminação e o racismo, a reconhecer a importância dos direitos fundamentais e a favorecer a inclusão e a plena participação de todos os cidadãos. Longe de ter se engajado na via integracionista que tomaram vários Estados europeus, a qual insiste fortemente nas responsabilidades dos novos imigrantes, o Estado quebequense, ao longo dos últimos anos, parece mais interessado no papel proativo que ele deve exercer para facilitar a integração e favorecer o respeito das minorias etnoculturais.

Há uma importante continuidade entre as quatro fases discutidas acima. Cada uma delas confirma a vontade renovada de instaurar uma política de integração e de gestão da diversidade etnocultural que rejeite a exigência da assimilação e que seja, ao mesmo tempo, capaz de assegurar a perenidade da identidade quebequense e do caráter francês no respeito das diferenças etnoculturais e de promover os direitos e as liberdades de todos os quebequenses.

\section{Os novos desafios da integração no Quebec}

O Quebec soube se constituir, nos últimos cinquenta anos, como uma sociedade de acolhida e como um polo de integração no seio do Canadá. Notadamente, ele soube acolher imigrantes ao mesmo tempo em que protegia a sua língua e a sua identidade francófonas. No entanto, muitos quebequenses ainda se lembram da época na qual os novos imigrantes tinham tendência a aprender o inglês e a não se integrar à sociedade

quebequense francófona (GAGNON, IACOVINO, 2007). É, portanto, pouco 
surpreendente que muitos deles exprimam seus temores quanto à capacidade do Quebec preservar a sua identidade distinta ao se manter aberto à diversidade etnocultural.

Assim, ao longo dos últimos anos, o objetivo de reconhecimento da realidade plural da população quebequense, afirmado no enunciado de política de 1990, foi freado. Em primeiro lugar, certa virada cívica, lançada em meados dos anos 1990, aplicada à definição da identidade quebequense, colocou em suspensão, por algum tempo, a noção de "comunidades culturais". Mais recentemente, no entanto, uma reorientação em torno da herança canadense francesa, em meio aos turbulentos debates sobre as acomodações razoáveis e a Carta dos Valores proposta pelo governo, contribuiu para desvalorizar o reconhecimento do caráter plural da sociedade quebequense.

As exigências de acomodações por motivos religiosos foram percebidas por alguns como sendo a expressão de uma recusa de integração por parte dos seus solicitantes, quer eles pertencessem ou não às minorias etnoculturais migrantes. Isto foi salientado até mesmo quando essas acomodações visavam a permitir aos seus solicitantes a plena participação nas instituições públicas comuns ou a entrada no mercado de trabalho, conservando, simultaneamente, certas práticas distintivas que não violavam os direitos de outrem, o bom funcionamento das instituições e das empresas e que não impunham um fardo financeiro elevado. Nós pudemos observar nos últimos anos a ascensão de uma tendência consistindo em considerar as práticas culturais ou religiosas das minorias etnoculturais como sendo incompatíveis com a identidade quebequense. A partir da "crise" das acomodações razoáveis, nós pudemos constatar que o caráter religioso de várias reivindicações formuladas por membros de minorias foi descrito como sendo irreconciliável com o princípio de integração e com os valores sobre os quais se fundamentaria a identidade quebequense. Estas inquietações foram reiteradas ao longo dos recentes debates em torno da Carta dos Valores Quebequenses.

Nós não poderíamos ignorar que o Quebec está em busca de uma laicidade (pensemos no projeto de Carta dos Valores Quebequenses, de 2013-2014, nas recomendações do relatório Bouchard-Taylor, nas intervenções do Movimento Laico Quebequense, etc.), cujos contornos são imprecisos. Esta busca pela laicidade incide sobre as percepções e as atitudes dos quebequenses em relação às medidas a serem tomadas 
para facilitar a integração dos novos imigrantes no respeito dos direitos fundamentais e do direito à diferença. $\mathrm{O}$ Quebec acaba de concluir o processo de desconfessionalização de seu sistema escolar. Na esteira dos trabalhos da Comissão dos Estados Gerais da Educação (1995-1996) e do Grupo de Trabalho sobre o Papel da Religião na Escola (1999), a Assembleia Nacional adotou, em junho de 2000, a Lei Modificando Diversas Disposições Legislativas sobre a Confessionalidade no Setor da Educação, que colocou fim ao estatuto confessional das escolas públicas primárias e secundárias do Quebec. As comissões escolares confessionais (católicas e protestantes) se tornaram comissões escolares linguísticas (após a modificação do Artigo 93 da Constituição Canadense). O ensino religioso foi substituído, em 2008, por um programa de ética e de ensino cultural das religiões (Ética e Cultura Religosa). Assim, alguns membros da maioria francófona (e católica) tomaram consciência da prática de acomodações razoáveis por motivos religiosos em instituições públicas no exato momento em que o ensino católico deixava de ser oferecido na escola pública. Isto contribuiu, sem dúvidas, para reforçar a percepção segundo a qual a maioria histórica do Quebec desaparece enquanto a identidade das minorias etnorreligiosas se afirma cada vez mais na esfera pública. Esta percepção foi um dos fatores explicativos do refluxo sentido em relação ao acomodamento da diversidade.

Em resumo, entre os desafios que se impõem ao conjunto dos quebequenses nós pudemos destacar o sentimento, presente entre uma parte dos membros da maioria histórica francófona, que a diversidade etnocultural e a imigração poderiam ameaçar a identidade quebequense e os seus valores. Igualmente, se verifica uma preocupação com o distanciamento dos novos imigrantes, que dariam as costas à sociedade de acolhida. Estes sentimentos não se apoiam em dados cientificamente confirmados, mas eles contribuem à criação de um fosso entre os quebequenses de imigração mais recentemente e o restante da população.

Nestes últimos anos, os debates que permearam o conjunto da população quebequense se concentraram mais no dever de integração das pessoas migrantes e menos no enriquecimento mútuo, nas trocas intercomunitárias e no uso da língua francesa no mercado de trabalho. As discussões e as iniciativas visando a promover a integração se referiram, sobretudo, às balizas das acomodações razoáveis, assim como à definição 
da identidade quebequense por meio da clarificação dos "valores" que constituiriam a sua base. Todavia, a mais recente política do governo quebequense (A diversidade: um valor agregado, de 2008) e seu plano de ação adotado para o período 2008-2013 parecem tomar outra direção. Esta abordagem busca sensibilizar a população acerca da chegada dos novos quebequenses e pensar políticas que permitam superar os obstáculos entravando a plena participação de todos e o respeito das diversas coletividades culturais. Se nós pudemos testemunhar a ocorrência de um refluxo contra o pluralismo no conjunto da população, constatamos que ele não se traduziu em medidas legislativas.

O Quebec entra em um período no qual os desafios a serem superados serão numerosos. O gênio e a abertura dos quebequenses à diversidade deverão se fazer presentes para que se imaginem vias criativas de aproximação e de convergência para o conjunto das coletividades que virão assentar a especificidade da província na escala internacional. É essencial dar ainda mais importância aos temas da participação e das trocas interculturais. Isto contribuiria 1) a barrar a reprodução de certos estereótipos e preconceitos que sinalizam novas formas de discriminação; e 2) a evitar o isolamento das coletividades e fazer com que a desconfiança não se instale entre elas.

A fim de elaborar um plano de ação propulsor, será seguramente necessário que as próximas políticas governamentais adotadas possam deter a discriminação sistêmica que prejudica a participação socioeconômica e política de todos os cidadãos e, particularmente, dos novos imigrantes. O sucesso desta proposição contribuiria para criar um contexto favorável à instauração de mais justiça social e igualdade entre os cidadãos e à consolidação, de fato, das condições da diversidade no Quebec.

Traduzido do francês por Oscar Augusto Berg. ${ }^{18}$

\section{Referências}

ANG, Ien; BRAND, Jeffrey; NOBLE, Greg; STERNBERG, Jason. Connecting Diversity: Paradoxes of Multicultural Australia. Humanities and Social Science Papers, 2006. Disponível em: <http://epublications.bond.edu.au/hss_pubs/20>.

BANTING, Keith; KYMLICKA, Will. Is there really a retreat from multiculturalism policies? New evidence from the multiculturalism policy index. Comparative European Politics, v. 11, 2013, p. 577-598. 
. Les politiques du multiculturalisme nuisent-elles à l'État-providence? Lien social et politiques, v. 53, 2005, p. 119-127.

BOUCHARD, Gérard. L'interculturalisme. Un point de vue québécois. Montreal: Boréal, 2012.

BOUCHER, François; MACLURE, Jocelyn. L'obligation d'accommodement raisonnable dans les sociétés pluralistes: enjeux et perspectives. In: BRIBOSIA, Emmanuelle; RORIVE, Isabelle (Org.). L'accommodement de la diversité religieuse. Regards croisés Canada, Europe, Belgique. Bruxelas: Peter Lang, 2015.

BRUBACKER, Rogers. The Return of Assimilation? Changing Perspective on Immigration and its Sequels in France, Germany, and the United States. Ethnic and Racial Studies, v. 24, n. 4, 2011, p. 531-548.

CANTLE, Ted. Cohesion and Integration: From 'Multi' to 'Inter' Culturalism. In: BOUCHARD, Gérard; BATTAINI-DRAGONI, Gabriella; SAINT-PIERRE, Céline; NOOTENS, Geneviève; FOURNIER, François (Org.). L'interculturalisme. Dialogue Québec-Europe. Quebec: Bibliothèque et Archives nationales du Québec, 2011.

CARDINAL, Linda; SONNTAG, Selma (Org.). Language Regimes and State Traditions. Montreal e Kingston: McGill-Queen's University Press, 2014.

COMMISSION D'ENQUÊTE SUR LA SITUATION DE LA LANGUE FRANÇAISE ET SUR LES DROITS LINGUISTIQUES AU QUÉBEC. Rapport de la Commission d'enquête sur la situation de la langue française et sur les droits linguistiques au Québec: la langue de travail. Quebec: Éditeur officiel, 1972.

CONSEIL DE L'EUROPE. Les actions de l'UE pour que l'intégration fonctionne. Principes de base communs. Estrasburgo: Conseil de l'Europe, 2004. Disponível : $<$ htpp://ec.europa.eu/ewsi/fr/EU_actions_integration.cfm $>$.

. Livre Blanc sur le dialogue interculturel: vivre-ensemble dans l'égale dignité. Estrasburgo: Conseil de l'Europe, 2008.

ENTZINGER, Han. The Parallel Decline of Multiculturalism and the Welfare State in the Netherlands. In: BANTING, Keith; KYMLICKA, Will (Org.). Multiculturalism and the Welfare State: Recognition and Redistribution in Contemporary Democracies. Oxford: Oxford University Press, 2006.

GAGNON, Alain-G.; IACOVINO, Raffaele. De la nation à la multination. Les rapports Canada-Québec. Montreal: Boréal, 2007.

. Interculturalism and Multiculturalism: Similarities and Differences. In: MEER, Nasar; MODOOD, Tariq; ZAPATA-BARRERO, Ricard (Org.). Multiculturalism and Interculturalism: Debating the Dividing Lines. Edimburgo: Edinbugh University Press, 2016. p. 104-132.

GAGNON, Alain-G.; KEATING, Michael (Org.). Political Autonomy and Divided Societies: Imagining Democratic Alternatives in Complex Settings. Basingstoke: Palgrave Macmillan, 2012. 
GLAZER, Nathan. We are All Multiculturalists Now. Cambridge: Harvard University Press, 1998.

GOODMAN, Sara Wallace. Fortifying Citizenship: Policy Strategies for Civic Integration in Western Europe. World Politics, v. 64, n.3, 2012, p. 659-698.

HUNTINGTON, Samuel. Who Are We? The Challenges to America's National Identity. Londres: Simon \& Schuster, 2005.

JOPPKE, Christian. The Retreat of Multiculturalism in the Liberal State: Theory and Policy. The British Journal of Sociology, v. 55, n. 2, 2004, p. 237-257.

. The Role of the State in Cultural Integration: Trends, Challenges and Ways Ahead. Washington: Migration Policy Institute, 2012.

JOPPKE, Christian; SEIDLE, Leslie. Introduction. In: JOPPKE, Christian; SEIDLE, Leslie (Orgs.). Immigrant integration in Federal Countries. Montreal e Kingston: McGill-Queen's University Press, 2012.

KYMLICKA, Will. Defending Diversity in an Era of Populism: Multiculturalism and Interculturalism Compared. In: MEER, Nasar; MODOOD, Tariq; ZAPATA-BARRERO, Ricard (Org.). Multiculturalism and Interculturalism: Debating the Dividing Lines. Edimburgo: Edinbugh University Press, 2016. p. 158-177.

. Multiculturalism: Success, Failure, and the Future. Washington: Migration Policy Institute, 2012.

. Politics in the Vernacular: Nationalism, Multiculturalism and Citizenship.

Oxford: Oxford University Press, 2001.

. Testing the Liberal Multiculturalist Hypothesis: Normative Theories and Social Science Evidence. Revue canadienne de science politique, v. 43, n. 2, 2010, p. 257-271.

KYMLICKA, Will; NORMAN, Wayne. Citizenship in Culturally Diverse Societies: Issues, Contexts, Concepts. In: KYMLICKA, Will; NORMAN, Wayne (Org.) Citizenship in Diverse Societies. Oxford: Oxford University Press, 2000.

LAURIN, Camille. Le français, langue du Québec: discours prononcés par Camille Laurin, ministre d'État au développement culturel et parrain de la Charte de la langue française, de mars à octobre 1977. Montreal: Éditions du Jour, 1978.

MEER, Nasar; MODOOD, Tariq. How does interculturalism contrasts with multiculturalism? Journal of Intercultural Studies, v. 33, 2012, p. 175-196.

MINISTÈRE DE L'IMMIGRATION ET DES COMMUNAUTÉS CULTURELLES.

La diversité: une valeur ajoutée. Plan d'action gouvernemental pour favoriser la participation de tous à l'essor du Québec 2008-2013. Quebec: Bibliothèque et Archives nationales du Québec, 2008.

. Vers une nouvelle politique québécoise en matière d'immigration, de diversité et d'inclusion. Quebec: Bibliothèque et Archives nationales du Québec, 2014. 
MINISTĖRE DES COMMUNAUTÉS CULTURELLES ET DE L'IMMIGRATION. $A u$ Québec, pour bâtir ensemble. Énoncé de politique en matière d'immigration et d'intégration. Québec: Direction des communications du ministère des Communautés culturelles et de l'Immigration du Québec, 1990.

. Autant de façons d'être québécois: plan d'action du gouvernement du Québec à l'intention des communautés culturelles. Quebec: Développement culturel et scientifique, 1981.

PAPADEMETRIOU, Demetrios. Rethinking National Identity in the Age of Migration. Washington: Migration Policy Institute, 2012.

SCHEFFER, Paul. Immigrant Nations. Malden: Polity Press, 2011.

SOROKA, Stuart; JOHNSTON, Richard; BANTING, Keith. Ties That Bind? Social Cohesion and Diversity in Canada. In: BANTING, Keith; COURCHENE, Thomas; SEIDLE, Leslie (Org.). The Art of the State. Volume III. Montreal e Kingston: McGillQueen's University Press, 2007, p. 561-600.

VERTOVEC, Steve; WESSENDORF, Susanne. The Multiculturalism Backlash: European Discourses, Policies and Practices. Londres: Routledge, 2010.

WEINSTOCK, Daniel. Interculturalism and Multiculturalism in Canada and Quebec. Situating the Debate. In: BALINT, Peter; GUÉRARD DE LA TOUR, Sophie (Org.). Liberal Multiculturalism and Fair terms of Integration. Basingstoke: Palgrave Macmillan, 2013. p. 91-108.

\section{Notes}

1 Tradução da obra: GAGNON, Alain-G.; BOUCHER, François. L’État québécois devant les défis de la diversité ethnoculturelle. In: GAGNON, Alain-G.; ST-CHARLES, Louis (Org.). Les conditions du dialogue au Québec: laïcité, réciprocité, pluralisme. Montreal: Éditions Québec-Amérique, Collection Débats, 2016, p. 173-196. Os artigos deste livro foram escritos em parceria entre os dois autores, cabendo metade da pesquisa e da redação a cada um. Ambos integram a mesma equipe há décadas. A tradução ao português foi concedida gratuitamente pela Editora Québec-Amérique e foi realizada de maneira benévola por Oscar Augusto Berg.

2 Université du Québec à Montréal, Departamento de Ciência Política, Montreal, Quebec, Canadá. E-mail: gagnon.alain@uqam.ca

${ }^{3}$ Université de Montréal, Centro de Pesquisa em Ética, Montreal, Quebec, Canadá. E-mail: f.boucher@ucl. ac.uk

${ }^{4}$ Este texto se inspira de nossas reflexões feitas no âmbito dos trabalhos que realizamos a convite do Ministério da Imigração, da Diversidade e da Inclusão (MIDI) ao longo do ano 2014 e que levaram à publicação de um relatório redigido com vários pesquisadores totalmente a par dos desafios que o Quebec deveria superar nestas matérias. É possível consultar o trabalho de síntese de nossos trabalhos: GAGNON, Alain-G.; MILOT, Micheline; SEIDLE, Leslie; BOUCHER, François. Rapport presente au ministère de l'Immigration, de la Diversité et de l'Inclusion en vue d'élaborer un nouvel énoncé de politique. Québec: MIDI, Études et recherches, 2014. Disponível em: <http://www.midi.gouv.qc.ca/publications/fr/recherchesstatistiques/ETU_AmenagDiversite_GanonMilotSeidleBouchard.pdf $>$

5 A política do multiculturalismo destaca um conjunto de medidas, dentre as quais a afirmação do multiculturalismo na Constituição ou pelos eleitos, nas esferas central, provincial ou municipal de governo; a adoção do multiculturalismo nos programas escolas; a inclusão da representação de grupos étnicos e da sensibilização à sua realidade no mandato das mídias públicas ou nas condições a serem respeitadas para a obtenção de uma licença de difusão; a existência de isenções relacionadas ao código vestimentário; a outorga 
da dupla nacionalidade; o financiamento de organizações ou atividades étnicas; o financiamento do ensino bilíngue ou em uma língua materna; a discriminação positiva para os grupos de imigrantes desfavorecidos.

${ }^{6}$ Discurso pronunciado no Congresso da Juventude da CDU, em Potsdam, em 16 de outubro de 2010. Ver WAEVER, Matthew. Angela Merkel: German multiculturalism has utterly failed. The Guardian, Londres, 17 out. 2010. David Cameron e Nicolas Sarkozy deram declarações semelhantes, o primeiro em seu discurso pronunciado quando da Conferência de Munique sobre a Segurança, em 5 de fevereiro de 2011, e o segundo no âmbito de uma entrevista concedida ao programa Paroles de français (TF1), em 10 de fevereiro de 2011.

7 Discurso pronunciado em Munique, em 5 de fevereiro de 2011, disponível em: <http://www.bbc.co.uk/ news/uk-politics-12371994>.

${ }^{8}$ Ver SOROKA, Stuart; JOHNSTON, Richard; BANTING, Keith, op. cit.; MAY, Paul. Politiques de reconnaissance et redefinition de la laïcité: quelles consequences sur les droits individuels? Le cas des tribunaux d'arbitrage en Ontario (Tese de Doutorado em Ciência Política) - Université du Québec à Montréal, 2013.

9 Au Québec, pour bâtir ensemble, no original em francês [N. do T.].

${ }^{10}$ A Carta dos Valores Quebequenses era um projeto de lei proposto pelo governo de Pauline Marois para modificar a Carta Quebequense dos Direitos e Liberdades do Pessoa e afirmar a neutralidade religiosa do Estado quebequense. Ela proibia, notadamente, o uso de símbolos religiosos ostensivos, como o turbante, o hijab e a quipá, por funcionários públicos do Quebec na prestação de serviço. A Carta dos Valores suscitou uma viva reação da população quebequense, que se dividiu quanto à sua aprovação. A derrota de Pauline Marois nas eleições de abril de 2014 significou o abandono deste controverso projeto de lei pelo governo sucessor [N. do T.].

${ }^{11}$ Nós podemos qualificar a relação que o Quebec mantém com as Primeiras Nações de "póscolonial". Todavia, o Quebec não tem uma relação póscolonial com as suas minorias oriundas da imigração, contrariamente à França, que entretém este tipo de relação histórica com a importante minoria de origem argelina.

${ }^{12}$ A Crise das Acomodações Razoáveis consiste em um conjunto de casos amplamente midiatizados envolvendo a outorga de acomodações por motivos religiosos para que minorias etnoreligiosas do Quebec pudessem exprimir suas identidades cultural e religiosa e que suscitou uma ampla controvérsia no seio da maioria francófona. Para responder à crise, o governo do Quebec instaurou a Comissão Bouchard-Taylor, em 2007, para formular sugestões sobre a prática de acomodações religiosas, as quais foram apresentadas em 2008 por meio do relatório Le temps de la réconciliation [N. do T.].

${ }_{13}$ Discurso proferido pelo Sr. Camille Laurin, Ministro de Estado ao Desenvolvimento Cultural durante o colóquio "Fronteiras Étnicas em Formação", em 5 de novembro de 1977, em Quebec.

${ }^{14}$ Autant de manières d'être québécois, no original em francês [N. do T.].

${ }^{15}$ Ver, por exemplo, CONSEIL DE L'EUROPE. Livre Blanc sur le dialogue interculturel: vivre-ensemble dans l'égale dignité. Estrasburgo: Conselho da Europa, 2008.

${ }^{16}$ Ver ROCHER, François; LABELLE, Micheline; FIELD, Ann-Marie; ICART, Jean-Claude. Le concept d'interculturalisme en contexte québécois: généalogie d'un néologisme. Rapport présenté à la Commission de consultation sur les pratiques d'accommodement reliées aux différences culturelles. Montreal: Centre de recherche sur l'immigration, l'ethnicité et la citoyenneté, Université du Québec à Montréal, 2007; BOUCHARD, Gérard; BATTAINI-DRAGONI, Gabriella; SAINT-PIERRE, Céline; NOOTENS, Geneviève; FOURNIER, François (Orgs.). L'interculturalisme. Dialogue Québec-Europe. Quebec: Bibliothèque et Archives nationales du Québec, 2011; EMONGO, Lomomba; WHITE, Bob W. (Orgs.). L'interculturel au Québec. Rencontres historiques et enjeux politiques. Montreal: Presses de l'Université de Montréal, 2014; MEER, Nasar; MODOOD, Tariq; ZAPATA-BARRERO, Ricard (Orgs.). Multiculturalism and Interculturalism: Debating the Dividing Lines. Edimburgo: Edinbugh University Press, 2016.

17 Ver PAREKH, Bhikhu. Rethinking Multiculturalism: Cultural Diversity and Political Theory. Cambridge: Harvard University Press, 2002. P. 264-294.

18 Pontifícia Universidade Católica do Rio Grande do Sul, Mestrando no Programa de Pós-Graduação em Ciências Sociais, Porto Alegre, RS, Brasil. E-mail: oscar.b5@hotmail.com 